\title{
The Effect of Vocal Fold Steroid Injection via Cricothyroid Membrane in Patients with Vocal Polyp
}

\author{
Woojoo Nam ${ }^{\mathbb{D}}$, Seung Ho Noh, Jin Lee, Sun Woo Kim, Sung Min Jin, and Sang Hyuk Lee $\mathbb{C}$ \\ Department of Otorhinolaryngology-Head and Neck Surgery, Kangbuk Samsung Hospital, Sungkyunkwan University School of \\ Medicine, Seoul, Korea
}

\author{
성대 용종 환자에서 경윤상 갑상막 접근을 통한 성대 내 스테로이드 주입술의 효과 \\ 남우주·노승호·이 진 · 김선우 · 진성민 · 이상혁 \\ 성균관대학교 의과대학 강북삼성병원 이비인후과학교실
}

Received July 13, 2019

Revised August 11, 2019

Accepted September 26, 2019

Address for correspondence

Sang Hyuk Lee, MD

Department of Otorhinolaryngology-

Head and Neck Surgery,

Kangbuk Samsung Hospital,

Sungkyunkwan University

School of Medicine,

29 Saemunan-ro, Jongno-gu,

Seoul 03181, Korea

Tel +82-2-2001-2269

Fax $+82-2-2001-2412$

E-mail entlsh@hanmail.net
Background and Objectives Vocal polyps are generally caused by phonotrauma such as vocal overuse, and the first line treatment is known as laryngeal microsurgery. The aim of the study is to evaluate the applicability and effectiveness of percutaneous steroid injection via cricothyroid membrane in patients with vocal polyp and to evaluate its advantages and limitations of the technique.

Subjects and Method We included in this study 70 patients with vocal polyp managed by vocal fold steroid injection via the cricothyroid membrane from Jan 2008 to July 2018. We compared their medical records of laryngoscopy, stroboscopy, and multi-dimensional voice program analysis at pre and post treatment. Subjective voice improvement was evaluated using Voice Handicap Index-30 (VHI-30).

Results Of the patients, 54.3 percent showed morphological improvement. In acoustic analysis, the pre-treatment mean values of jitter, shimmer, and NHR were $2.20 \pm 2.23,5.09 \pm 3.24$, $0.15 \pm 0.04$, respectively. The post-treatment values were $1.54 \pm 1.28,5.00 \pm 4.40,0.13 \pm 0.04$, respectively, and only jitter was statistically significant. For subjective symptom improvement, $32(45.8 \%)$ patients showed better score on the post-treatment of VHI-30 compared to pretreatment. Ten patients experienced mild complications such as vocal fold atrophy and scar; however, no critical complications such as internal bleeding or dyspnea were reported.

Conclusion According to our study, steroid injection is a safe and effective procedure for patients with vocal polyp. A vocal fold steroid injection via the cricothyroid membrane can be an alternative treatment option for those who are not able to undergo conventional laryngeal microscopic surgery. Korean J Otorhinolaryngol-Head Neck Surg 2020;63(11):511-6

Key Words Steroid injection · Treatment · Vocal fold · Vocal polyp · Voice.
서 론

성대 용종은 과도한 음성 사용 혹은 기침 등이 성대의 고 유층(lamina propria)의 천층(superficial layer)에 물리적인 손상을 가하여 발생하는 질환이다." 작은 크기의 성대 용종

This is an Open Access article distributed under the terms of the Creative Commons Attribution Non-Commercial License (https://creativecommons.org/licenses/by-nc/4.0) which permits unrestricted non-commercial use, distribution, and reproduction in any medium, provided the original work is properly cited.
은 보존적 치료만으로도 자연적으로 소실되기도 하지만 대부 분의 경우 1차 치료로는 전신마취하 후두 미세수술로 알려져 있다. ${ }^{23)}$ 하지만 경우에 따라서는 기저질환이나 개인적 사유로 인해서 전신마취가 불가능한 경우 음성 치료나 성대 내 스테 로이드 주입술을 시행한 연구들이 보고되었다.,5) 음성 치료 의 경우는 성대결절보다는 효과가 적어 $20 \%$ 정도에서만 호전 을 보이며, 2 3개월의 기간이 필요하고 음성위생을 지속적으 로 유지하여야 하는 불편함이 있다. ${ }^{6,7}$ 
성대 내 스테로이드 주입술은 국소마취하 경구개 혹은 경 비강으로 굴곡후두 내시경을 이용하는 동시에 경구강 혹은 경피적으로 주사기를 이용하여 성대 내에 스테로이드를 주입 하는 시술이다. 레인케씨 공간에 높은 농도의 스테로이드를 국소적으로 주입할 수 있고 스테로이드의 전신 작용 없이 시 술을 할 수 있는 것이 장점이다. ${ }^{5)}$ 경구개로 굴곡후두 내시경 을 통한 성대 내 스테로이드 주입술도 보고되었으나 환자의 구역반사가 심한 경우에는 시행이 매우 어려웠으며 성대의 고유층을 관통하여 주사하여야 하기 때문에 고유층에 반흔 이 생기며 재생이 잘 되지 않는 문제점도 보고된 바 있다. ${ }^{8}$

본 연구에서는 성대 용종 환자에서 성대 내 스테로이드 주 입술로 병변이 호전되는 정도와 환자의 음성수치의 개선 및 주관적인 증상 호전 여부를 알아보고 시술에 따른 합병증을 알아보고자 하였다.

\section{대상 및 방법}

2008년 1월 2018년 7월까지 강북삼성병원 이비인후과를 내원하여 성대 용종으로 경윤상 갑상막 접근을 통한 성대 내 스테로이드 주입술을 시행받은 환자를 대상으로 후향적 연구를 시행하였다(IRB No. 2019-11-038). 성대 용종은 70 Rigid Telescope $\left(\mathrm{COMEG}^{\circledR}\right.$, Budapest, Hungary)를 이용한 후두 스트로보스코피 검사나 일반 후두 내시경을 통하여 진 단하였다.

성대 내 스테로이드 주입술은 먼저 환자의 비강 및 비인두 의 마취를 위해 4\% lidocaine과 1:2000 epinephrine이 적셔 진 pledget 거즈를 비강 내에 패킹하고 윤상갑상막 부위의 피 부의 마취를 위해 2\% lidocaine과 1:100000 epinephrine이 포함된 주사액을 주입하였다. 또한 구인두의 마취를 위해 $10 \%$ lidocaine hydrochloride를 구인두에 분무하였다. 보조 자는 굴곡형 후두경을 이용해 시술자에게 성대를 보여주고 시술자는 환자의 전면에서 triamcinolone acetonide suspension $(40 \mathrm{mg} / \mathrm{mL})$ 을 $26 \mathrm{G}$ 바늘을 이용하여 윤상갑상막을 통과하여 성대의 피하층에 주입하였다. 환자는 시술 후 24시 간 동안 음성 안정을 취하도록 하였다.

성대 내 스테로이드 주입술의 치료 효과를 평가하기 위하 여 2명의 전문의가 치료 전과 후의 스트로보스코피 또는 내 시경 소견을 이용하여 비교하였다. 시술 전 후두 영상과 시 술 약 4 8주 후의 정지 영상을 비교하여, 용종이 완전히 없 어진 경우는 완전소실, 전체 병변 부피의 약 $50 \%$ 이상 크기 가 감소하였으나 병변이 남아있는 경우는 일부 반응, 그 외의 경우는 무반응의 3군으로 분류하여 분석하였다.

음향학적 분석은 Multi-Dimensional Voice Program
(Model 4500; Kay Elemetrics Corp., Lincoln Park, NJ, USA) 을 이용하였다. 마이크에서 $10 \mathrm{~cm}$ 떨어진 거리에서 가장 편안 한 높이와 크기의 목소리로 2 3초간 /a/ '아'의 발성을 3회 반 복하도록 하였다. 발성된 음성은 $25 \mathrm{kHz}$ 의 sampling rate로 채 취하였고 3 회 측정한 음성 표본 중에서 가장 안정된 것을 골라 연속된 3초 구간을 분석하였다. 음향 변수로는 jitter, shimmer, noise to harmonic ratio(NHR)를 선택하였다. 공기역학적 검사 에서는 Aerophone II(Voice function analyzer, Kay Elemetric Corp.)를 이용하여 기본 단모음 /a/ '아를 발성하도록 하여 가 장 안정되고 편안하게 발성된 소리를 선택한 후 최장발성 지속 시간(maximum phonation time)을 3회 측정하였고 이 중 최 대치를 사용하였다. 시술 전 시행한 음향학적 분석과 시술 4 8주 후의 검사 결과를 비교하였다.

주관적인 증상의 호전 정도는 한국어판 음성장애지수-30 Voice Handicap Index(VHI)를 이용하여 시술 전과 시술 4 8주 후의 점수를 비교하여 분석하였다. 설문은 emotion$\mathrm{al}$, functional, physical 세 가지 분류에서 각 10 가지 세부항 목으로 구성되어 있고, 각 항목의 점수를 0 4점까지 환자가 답을 한 후 합산하여 산출하였다.

수집된 자료는 통계 분석 프로그램 Statistics Package for the Social Sciences(SPSS Inc., version 15.0, Chicago, IL, $\mathrm{USA}$ )로 분석하였다. 각각의 항목에 대하여 시술 전후의 비교 는 Paired Student t-test를 실시하였고, 통계 검정상 $p<0.05$ 를 유의한 것으로 간주하였다.

\section{결 과}

총 70명의 성대 용종 환자가 본 연구에 포함되었고, 남성이 23 명, 여성이 47명으로 연령은 17 86세까지 분포하였으며 평 균 연령은 49.45세였다. 성대 용종은 모두 일측으로 좌측이 33 명, 우측이 37명이였다. 성대 내 스테로이드 주입술을 1회만 시행받은 환자가 61 명, 2 회 시행받은 환자는 9 명으로 70 명에 서 시행한 총 횟수는 79회였다. 환자의 직업 중 성악가, 뮤지 컬 배우, 상담원 등 일반적으로 음성남용이 있을 수 있는 환

Table 1. Demographic features of the patients

\begin{tabular}{lc}
\hline & Value \\
\hline Total & 70 \\
Age $(\mathrm{yr})$ & $49.45 \pm 15.6$ \\
Sex $(\mathrm{M}: \mathrm{F})$ & $23: 47$ \\
Side (left:right) & $33: 37$ \\
Injection number of times (once:twice) & $61: 9$ \\
Injection volume (cc) & $0.175 \pm 0.084$ \\
\hline
\end{tabular}

Variables are presented as mean \pm standard deviation 
자는 10 명으로 확인되었다. 성대 내에 주입된 스테로이드의 용량은 0.1 0.2 cc로 평균 주사량은 $0.175 \mathrm{cc}$ 였다(Table 1).

성대 내 스테로이드 주입술 후 성대 용종의 형태학적 분석 에서는 총 70 명의 환자 중 6 명에서 성대 용종이 완전히 소실 되었고 32 명에서는 부분적 소실을 보였으나, 32명에서는 시 술 전과 비교하여 반응을 보이지 않았다(Table 2, Fig. 1). 첫 번째 스테로이드 주입 후 전혀 반응을 보이지 않은 무반응 환자군에게는 대부분 전신마취하 수술을 권유하였고, 일부 반응을 보인 환자군에서는 환자와 상의 후 두 번째 시술을
Table 2. Morphological evaluation comparing pre-treatment and post-treatment

\begin{tabular}{lcc}
\hline & $\mathrm{n}$ & $\%$ \\
\hline Disappeared & 6 & 8.5 \\
Partial response & 32 & 45.7 \\
No response & 32 & 45.7 \\
\hline
\end{tabular}

시행하였다. 성대 용종의 크기와 무경성(sessile), 유경성(pedunculated) 등 형태학적 차이, 성별, 주입 횟수, 음성남용 직 업군에 대하여 확인하였으나 각 항목에 대하여 통계적으로
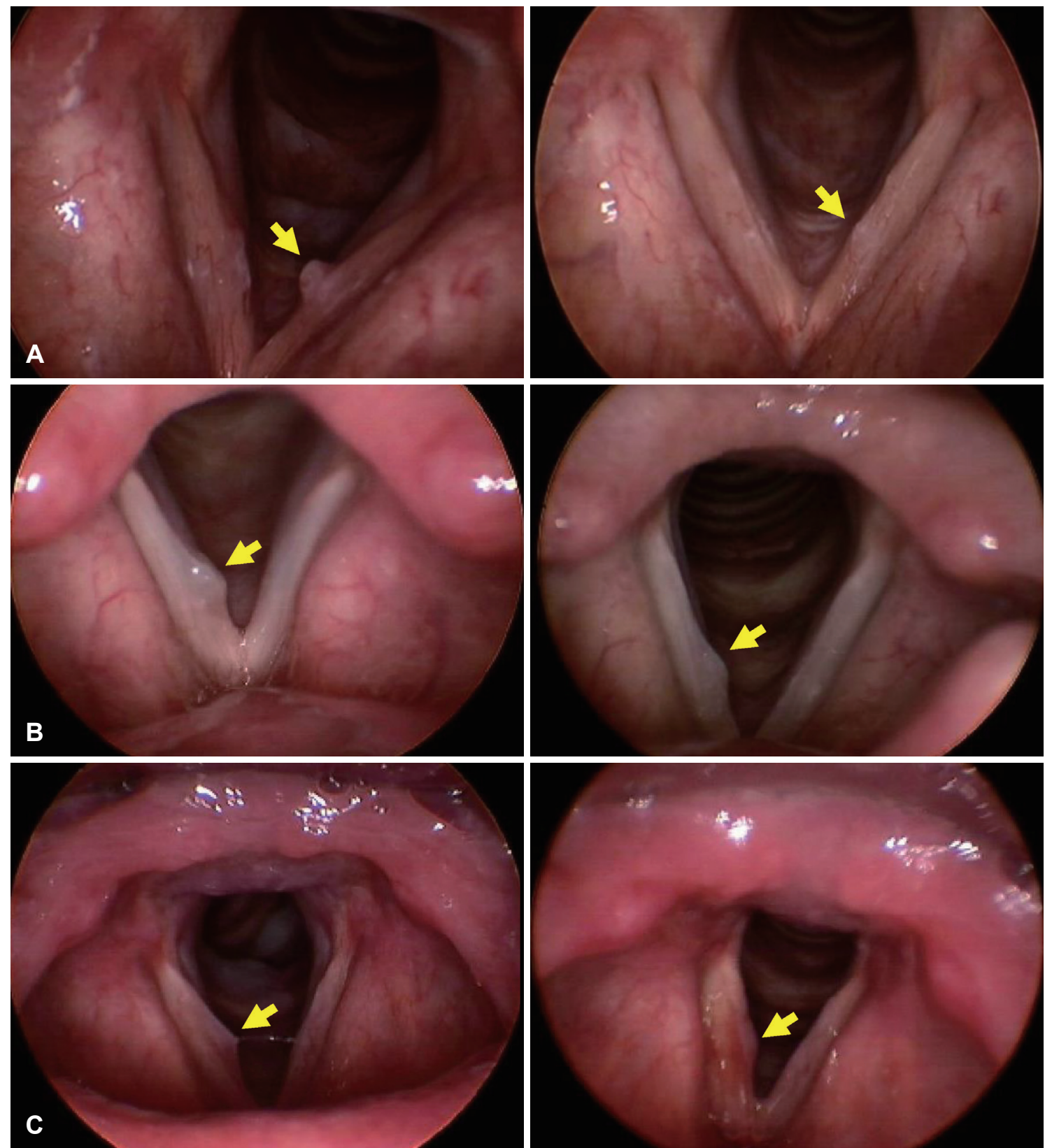

Fig. 1. Morphological analysis of comparing pre-treatment and post-treatment. Disappeared (A, arrows), partial response (B, arrows), no response (C, arrows). 
Table 3. The difference between pre-treatment and post-treatment in acoustic analysis

\begin{tabular}{lcccc}
\hline & Pre-treatment & Post-treatment & Difference & $p$-value \\
\hline Jitter & $2.20 \pm 2.23$ & $1.54 \pm 1.28$ & $0.66 \pm 1.44$ & 0.04 \\
Shimmer & $5.09 \pm 3.24$ & $5.00 \pm 4.40$ & $0.09 \pm 3.82$ & 0.91 \\
NHR & $0.15 \pm 0.04$ & $0.13 \pm 0.04$ & $0.01 \pm 0.04$ & 0.25 \\
MPT & $12.12 \pm 5.37$ & $15.45 \pm 3.16$ & $3.32 \pm 2.24$ & 0.03 \\
\hline
\end{tabular}

Variables are presented as mean \pm standard deviation. NHR: noise to harmonic ratio, MPT: maximum phonation time

Table 4. Subjective symptom improvement (Voice Hadicap Index-30) comparing pre-treatment and post-treatment

\begin{tabular}{lccc}
\hline & Pre-treatment & Post-treatment & p-value \\
\hline Emotional & $18.12 \pm 5.12$ & $9.13 \pm 2.16$ & 0.001 \\
Functional & $14.35 \pm 3.84$ & $13.21 \pm 4.23$ & 0.098 \\
Physical & $20.12 \pm 6.03$ & $19.25 \pm 5.02$ & 0.124 \\
Total & $52.59 \pm 5.28$ & $41.59 \pm 4.76$ & 0.036 \\
\hline
\end{tabular}

Variables are presented as mean \pm standard deviation

\section{유의한 차이는 관찰되지 않았다.}

음향학적 분석에서 시술 전 jitter, shimmer, NHR값은 각 각 $2.20 \pm 2.23,5.09 \pm 3.24,0.15 \pm 0.04$ 시술 후는 각각 $1.54 \pm$ $1.28,5.00 \pm 4.40,0.13 \pm 0.04$ 였다. 시술 전후의 각 항목의 평 균값의 차이는 $0.66 \pm 1.44,0.09 \pm 3.82,0.01 \pm 0.04$ 로 관찰되었 으며 시술 전에 비하여 각각 $30 \%, 1.7 \%, 6 \%$ 의 호전을 보였으 나 jitter값만 통계학적으로 유의한 호전을 보였다 $(p<0.05)$. 최장발성 지속시간은 수술 전의 평균값이 $12.12 \pm 5.37$, 시술 후의 평균값이 $15.45 \pm 3.16$ 으로 관찰되었으며 이는 통계학적 으로 유의한 차이를 보였다 $(p<0.05)$ (Table 3). 주관적인 호전 여부 판단을 위한 VHI-30 설문에서는 $45.8 \%$ 의 환자에서 시 술 전과 비교하여 호전을 보였으며 시술 전과 비교하여 emotional 항목에서만 유의한 차이를 보였다(Table 4).

총 70명의 환자 중에서 성대 내 주입술 후 경도의 성대 위축 이 4명, 성대의 백색 침전물 침착, 경도의 성대 부종이 각 한 명씩 확인되었다. 시술 중이나 시술 후 출혈이나 호흡곤란 등 합병증은 발생되지 않았고, 성대 위축과 백색 침전물도 1 2개 월 후 자연 소실되어 유의한 문제는 관찰되지 않았다(Fig. 2).

\section{고 찰}

대부분의 성대 용종은 음성남용이나 비효율적인 발성에서 기인한다. 성대고유층에 발생한 손상은 재생 과정에서 상피 와 천층에 모세혈관의 투과성이 증가하고 콜라겐이 축적된 다. 하지만 반복적인 물리적 외상이 가해지게 되면 이 과정이 방해를 받게 되어 성대 용종이 발생하게 된다. 반복적 외상 없이 1 회성의 고함이나 심한 기침에 의해서도 발생한다고 알 려져 있다. ${ }^{8)}$
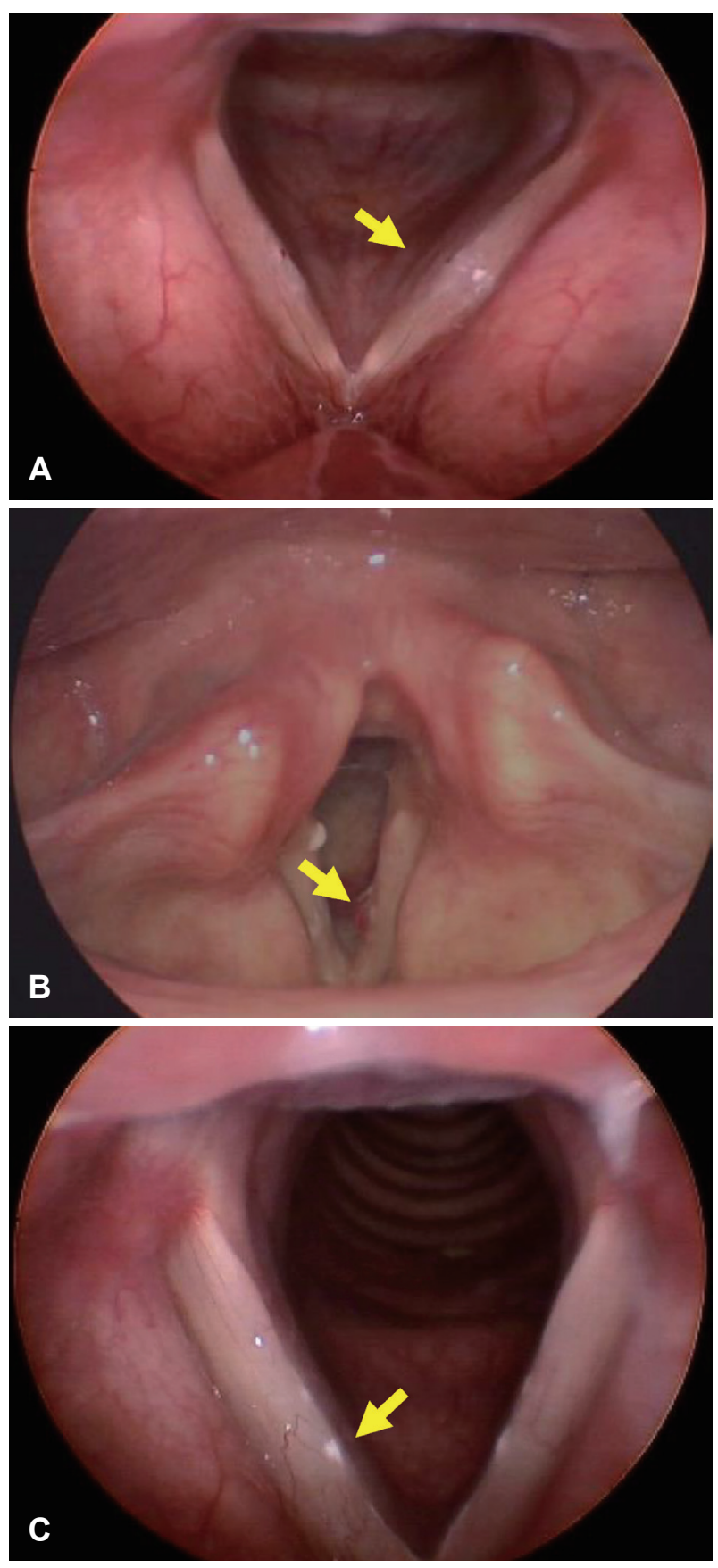

Fig. 2. Stroboscopic findings of post-treatment complications. Atrophy on right vocal fold (vocal ford bowing and decreased mucosal wave)(A, arrow). Hemorrhagic lesion on left vocal ford (B, arrow). Whitish plaque on right vocal ford ( $\mathrm{C}$, arrow). 
성대 용종, 성대결절, 레인케씨 부종 등 대부분의 양성 성 대병변의 치료는 음성 치료 혹은 후두 미세수술이 1차 치료 로 효과는 대체적으로 좋은 편이다. 다만 후두 미세수술의 경우 전신마취하에 시행되기 때문에 환자가 기저질환으로 인 해 전신마취가 불가능한 상황에서는 시행하기 어려운 단점 이 있다. 또한 의학적 문제 이외에도 경제적인 측면이나 입원 치료가 필요하기 때문에 환자의 순응도가 높은 편은 아니라 고 할 수 있다.

일부에서는 성대 용종 환자에서 대해 음성치료를 시행한 연구가 보고되었다. 여성에서 발생한 작은 용종이나, 크기가 작은 출혈성 용종에서는 음성치료의 효과가 특히 좋은 것으 로 알려져 있다." 한 연구에서는 수술의 비적응증에 해당되 거나 증상이 심하지 않은 경우에서 음성치료를 시행하였으 며 총 33 명 중 21 명에서 음성치료 후 용종이 소실되었다. 또 다른 연구에서는 음성위생교육을 처방하였으며 88명 중 $40 \%$ 정도에서 용종의 소실 혹은 뚜렷한 감소를 보였다. ${ }^{6.7)}$ 두 연구 모두 비침습적인 치료 방법으로 효과적인 결과를 얻었 으나 평균 추적 관찰 기간이 모두 3 개월 이상이며 음성남용 이 지속되는 경우에는 효과를 볼 수 없어 직업적으로 음성남 용이 불가피한 경우에는 제한이 있었다.) 또한 정상적인 성 대의 기능과 점막의 진동 회복을 통한 음성의 질적 효과를 위해서는 수술적인 치료가 필요하다고도 보고된 바 있다. ${ }^{10}$ 본 연구에서는 시술 이후 완전소실되지 않은 환자 중 3 명에 대해서는 음성치료를 시행하였으며 9명에 대해서는 후두 미 세수술을 시행하였다. 음성치료를 시행한 환자군은 경과 관 찰을 위해 재내원하지 않아 결과는 확인할 수 없었다. 수술 후의 음성치료는 이전의 많은 연구들에서 음성 회복에 도움 을 주는 것으로 알려져 있는데 음성 분석의 결과뿐 아니라 환자의 심리적 안정감이나 편안한 발성을 하는 데에도 효과 가 있다. ${ }^{11,12)}$

이전에 보고된 바에 따르면 22명의 성대 용종 환자를 대상 으로 스테로이드 주입술을 시행한 결과 환자의 $32 \%$ 에서 병변 의 부분적 호전이 관찰되었으며 $59 \%$ 에서는 완전 소실되었다 고 하였다. 형태학적으로뿐만 아니라 VHI 및 jitter, shimmer, NHR에서도 모두 유의한 호전을 보였다. ${ }^{4}$ 또 다른 연구에서는 스테로이드 주입술 후 $90 \%$ 이상에서 주관적인 증상 호전을 보고하였다. ${ }^{13)}$ 본 연구에서는 형태학적인 호전은 $54.3 \%$, 주관 적인 호전은 $45.8 \%$ 로 관찰되었다. 성대의 양성병변에 대하여 스테로이드 주입술을 시행한 연구에서는 성대결절, 레인케씨 부종, 성대 용종에 각각에 대하여 $35.7 \%, 35.7 \%, 28.6 \%$ 에서 형 태학적 호전을 보고하였다. ${ }^{5)}$ 저자들의 이전 연구에서 35 명의 성대결절 환자를 대상으로 스테로이드 주입술을 시행한 결과 93\%의 높은 치료 효과를 보였다. ${ }^{14)}$ 성대 용종에 대한 스테로
이드 주입술의 효과는 성대 결절과 비교하여 다소 떨어지지만 후두 미세수술을 시행할 수 없는 경우 대안이 될 수 있다. 또 한 타 기관의 연구에 비하여 본 연구의 치료 효과가 다소 떨어 지는 것으로 관찰되나 이는 대상군의 성대 용종의 크기, 병기 의 단계 혹은 성별의 구성 등 치료 효과에 영향을 미치는 요 소들이 상이하기 때문으로 생각된다.

성대 내 스테로이드 주입에서 주요 치료의 기전은 스테로 이드의 항염증 및 항부종 효과로 알려져 있다. ${ }^{4}$ 병변 조직으 로의 염증세포의 유출을 막고 다양한 염증매개체를 감소시 키면서 항염증 효과를 나타낸다. ${ }^{15)}$ 또한 섬유 아세포의 유사 분열을 막아 섬유화를 및 콜라겐 생성을 방해하여 용종의 지속적인 생성을 막는다. ${ }^{16}$

스테로이드의 단기적 경구 복용은 대체적으로 큰 부작용 을 야기하지 않으나 장기간의 복용은 전신 부작용의 가능성 이 있어 애성이나 발성장애 환자에서의 장기간 스테로이드의 복용은 권장되지 않는다. ${ }^{17)}$ 스테로이드는 강한 항염증 및 항 부종 효과가 있으며 주입된 스테로이드는 성대 내 레인케씨 공간(Reinke's space)에 높은 농도를 유지하며 머무를 수 있 다. 성대 내 주입술은 스테로이드의 가장 큰 부작용인 전신 작용이 나타나지 않으면서 염증을 억제할 수 있는 장점이 있 다. 스테로이드 주입술에서 술기 자체가 아닌 약물로 인해 이 론적으로 발생할 수 있는 부작용은 조직 위축과 창상 치유 과정의 지연 및 반흔 형성이 있는데 Tateya 등이 보고한 연구 결과에 따르면 5년 이후까지도 상기 부작용은 관찰되지 않았 다. ${ }^{18,19)}$ 본 연구 결과에서도 70 명 중 4명의 환자에서 성대 위 축이 보고되었으며 이전의 연구에서도 35 명 중 4 명의 환자에 서 발생하였다. ${ }^{15)}$ 토끼를 이용한 성대 내 스테로이드 주입술의 조직병리학적 효과 연구에 따르며 경도의 근위축의 경우에는 약 12 주 이내로 자연 회복되는 것으로 확인되었다. ${ }^{20)}$

성대 내 스테로이드 주입술은 후두 미세수술에 비하여 사 회경제적 비용이 적고 시술 시간도 짧으며 특히 불필요한 성 대의 반흔 형성이 없다는 점이 장점이다. 또한 비슷한 성대 내 주입술이라고 하더라도 경구강 성대 내 주입술의 경우 구 역반사가 심한 경우에는 시행이 어려우며 성대 내부가 아닌 외부에서 주입하기 때문에 후두 미세수술과 비슷하게 반흔 형성의 가능성이 있는 단점이 있다. ${ }^{18)}$ 경윤상갑상막 스테로이 드 주입술의 절대적 비적응증은 없는 것으로 생각되며 고령 이나 청소년의 경우에도 환자의 순응도만 따라준다면 시행 하여 볼 수 있다. 본 연구에서는 성대 용종의 치료로 일반적 으로 전신마취하 후두 미세수술을 시행하지만, 수술에 거부 감이 있거나 다른 기저질환으로 전신마취에 제한점이 있는 환자, 외래에서 성대 내 스테로이드 주입술을 원하는 환자가 포함되었다. 
본 연구는 후향적 연구 방법에 따른 경과 관찰 시기, 시술 전후의 검사 방법 및 시기의 차이 등에서 한계점이 있다. 시 술 결과에 영향을 줄 수 있는 요소로는 대상자의 음성남용 유무 및 직업, 용종의 크기 및 성상, 주입 용량에 따른 차이 등이 있을 수 있겠으며 추후 더 큰 대상군에서의 장기간의 전향적 연구가 필요할 것으로 사료된다.

성대 용종 환자에서 성대 내 스테로이드 주입술은 수술적 치료에 비하여 치료 효과가 적으나 음성치료 혹은 음성위생 교육에 비해서 비교적 빠른 시일 내에 효과를 원하는 환자에 서 적절히 시행한다면 효과적인 치료 방법이 될 것이다.

\section{Author Contribution}

Conceptualization: Sang Hyuk Lee. Data curation: Woojoo Nam, Jin Lee, Sun Woo Kim. Formal analysis: Woojoo Nam, Seung Ho Noh. Investigation: Woojoo Nam, Jin Lee. Methodology: Woojoo Nam, Sun Woo Kim. Software: Woojoo Nam. Supervision: Sung Min Jin, Sang Hyuk Lee. Validation: Sang Hyuk Lee. Writingoriginal draft: Woojoo Nam. Writing — review \& editing: Sung Min Jin, Sang Hyuk Lee.

\section{ORCIDs}

Sang Hyuk Lee https://orcid.org/0000-0003-4412-3486

Woojoo Nam https://orcid.org/0000-0002-5070-6939

\section{REFERENCES}

1) Walker P. Book review: Cummings otolaryngology-head and neck surgery. Ann Otol Rhinol Laryngol 2011;120(10):696.

2) Rubin JS, Sataloff RT, Korovin GS. Diagnosis and treatment of voice disorders. 4th ed. San Diego, CA: Plural Publishing;2014.

3) Srirompotong $S$, Saeseow P, Vatanasapt P. Small vocal cord polyps: Completely resolved with conservative treatment. Southeast Asian J Trop Med Public Health 2004;35(1):169-71.

4) Hsu Y-B, Lan M-C, Chang S-Y. Percutaneous corticosteroid injection for vocal fold polyp. Arch Otolaryngol Head Neck Surg 2009;135(8):776-80.

5) Lee SW, Park KN. Long-term efficacy of percutaneous steroid injection for treating benign vocal fold lesions: A prospective study. Laryngoscope 2016;126(10):2315-9.

6) Yun YS, Kim SW, Baek CH, Jeong HS, Son YI. Effect of vocal hygiene education in the patients with vocal polyp. Korean J Otorhinolaryngol-Head Neck Surg 2006;49(7):728-32.

7) Kim S-T, Jeong G-E, Kim S-Y, Choi S-H, Lim G-C, Han J-H, et al. The effect of voice therapy in vocal polyp patients. Phonetics and Speech Sciences 2009;1(2):43-9.

8) Ossoff RH, Shapshay SM, Woodson GE, Netterville JL. The larynx. Philadelphia, PA: Lippincott Williams \& Wilkins;2003.

9) Zhuge P, You H, Wang H, Zhang Y, Du H. An analysis of the effects of voice therapy on patients with early vocal fold polyps. J Voice 2016;30(6):698-704.

10) Lee SH. Non-surgical management for benign vocal fold lesions. J Korean Soc Laryngol Phoniatr Logop 2015;26(2):97-100

11) Ju YH, Jung K-Y, Kwon SY, Woo J-S, Cho J-G, Park M, et al. Effect of voice therapy after phonomicrosurgery for vocal polyps: A prospective, historically controlled, clinical study. J Laryngol Otol 2013;127(11):1134-8.

12) Seo IH, Moon J-H, Chung P-S, Lee SJ. Role and effectiveness of postoperative voice therapy in laryngeal microsurgery. Korean J Otorhinolaryngol-Head Neck Surg 2018;61(4):200-7.

13) Wang CT, Liao LJ, Cheng PW, Lo WC, Lai MS. Intralesional steroid injection for benign vocal fold disorders: A systematic review and meta-analysis. Laryngoscope 2013;123(1):197-203.

14) Lee S-H, Yeo J-O, Choi J-I, Jin H-J, Kim J-P, Woo S-H, et al. Local steroid injection via the cricothyroid membrane in patients with a vocal nodule. Arch Otolaryngol Head Neck Surg 2011;137(10):1011-6.

15) Brunton L, Chabner B, Knollman B. Goodman and Gilman's the pharmacological basis of therapeutics. 12th ed. New York, NY: McGraw-Hill Medical;2006. p.171-218.

16) Bailey BJ, Johnson JT, Newlands SD. Head and neck surgery -otolaryngology. 4th ed. Philadelphia, PA: Lippincott Williams \& Wilkins;2006.

17) Schwartz SR, Cohen SM, Dailey SH, Rosenfeld RM, Deutsch ES, Gillespie MB, et al. Clinical practice guideline: Hoarseness (dysphonia). Otolaryngol Head Neck Surg 2009;141(3 Suppl 2):S1-31.

18) Tateya I. Laryngeal steroid injection. Curr Opin Otolaryngol Head Neck Surg 2009;17(6):424-6.

19) Tateya I, Omori K, Kojima H, Hirano S, Kaneko K, Ito J. Steroid injection to vocal nodules using fiberoptic laryngeal surgery under topical anesthesia. Eur Arch Otorhinolaryngol 2004;261(9):489-92.

20) Jin HJ, Lee SH, Lee SU, Lee HS, Jin SM, Kim DH, et al. Morphological and histological changes of rabbit vocal fold after steroid injection. Otolaryngol Head Neck Surg 2013;149(2):277-83. 